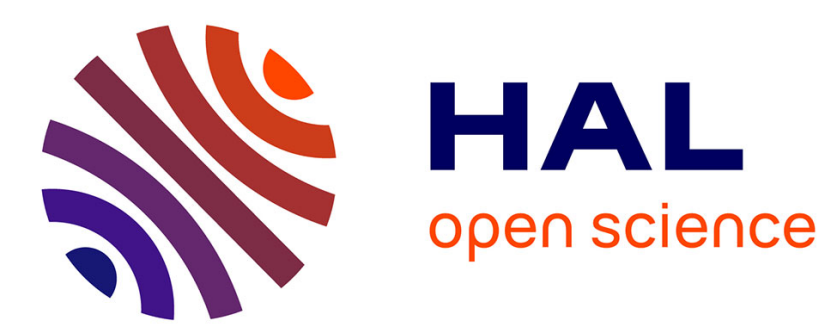

\title{
Microstructure-sensitive estimation of fatigue life using cyclic thermodynamic entropy as an index for metals
}

\author{
Arash P. Jirandehi, M.M. M Khonsari
}

\section{To cite this version:}

Arash P. Jirandehi, M.M. M Khonsari. Microstructure-sensitive estimation of fatigue life using cyclic thermodynamic entropy as an index for metals. Theoretical and Applied Fracture Mechanics, 2020, 112, pp.102854. 10.1016/j.tafmec.2020.102854 . hal-03106686

\section{HAL Id: hal-03106686 \\ https://hal.science/hal-03106686}

Submitted on 12 Jan 2021

HAL is a multi-disciplinary open access archive for the deposit and dissemination of scientific research documents, whether they are published or not. The documents may come from teaching and research institutions in France or abroad, or from public or private research centers.
L'archive ouverte pluridisciplinaire HAL, est destinée au dépôt et à la diffusion de documents scientifiques de niveau recherche, publiés ou non, émanant des établissements d'enseignement et de recherche français ou étrangers, des laboratoires publics ou privés. 


\title{
Microstructure-Sensitive estimation of fatigue life using cyclic thermodynamic entropy as an index for metals
}

\author{
Arash P. Jirandehi, M.M. Khonsari* \\ Louisiana State University \\ Department of Mechanical and Industrial Engineering \\ Baton Rouge, LA 70803, USA \\ *Corresponding Author Email: khonsari@1su.edu
}

\begin{abstract}
A technique for fatigue life prediction of metals is presented based on a microstructure-sensitive estimation of plastic strain energy per cycle. The approach enables rapid prediction of temperature evolution, estimation of cyclic plastic energy, and fracture fatigue entropy. Theoretical and experimental results are presented for low-carbon steel 1018 and aluminum 7075 T6 specimens. It is shown that the approach realistically predicts the fatigue life of metallic specimens.
\end{abstract}

Keywords: Fatigue life; fracture fatigue entropy; microplastic strain energy; microstructure effects

\begin{tabular}{|c|c|c|c|}
\hline \multicolumn{4}{|c|}{ Nomenclature } \\
\hline$A_{k}$ & $\begin{array}{l}\text { Associated function to internal } \\
\text { variables }\end{array}$ & $W_{p}$ & $\begin{array}{l}\begin{array}{l}\text { Plastic strain energy per cycle } \\
\left(\mathrm{MJ} / \mathrm{m}^{3} . \text { cycle }\right)\end{array}\end{array}$ \\
\hline$D$ & Deformation tensor & $Y$ & Yield limit of a macro-element (MPa) \\
\hline E & Elastic modulus (GPa) & $\epsilon_{k}$ & Strain of a micro-element \\
\hline$f(x)$ & $\begin{array}{l}\text { Weibull probability distribution } \\
\text { function }\end{array}$ & $\varepsilon_{e}$ & Thermoelastic strain \\
\hline$h$ & $\begin{array}{l}\text { Convective heat transfer coefficient } \\
\left(\mathrm{W} / \mathrm{m}^{2} \cdot \mathrm{K}\right)\end{array}$ & $\varepsilon_{p}$ & Plastic strain \\
\hline$K$ & Hardening coefficient (MPa) & $\rho$ & Density $\left(\mathrm{Kg} / \mathrm{m}^{3}\right)$ \\
\hline$n$ & Hardening exponent & $\Psi$ & Helmholtz free energy \\
\hline$N_{f}$ & Fatigue life (Cycles) & $\sigma$ & Stress $(\mathrm{MPa})$ \\
\hline$K$ & Hardening coefficient (MPa) & $\alpha$ & Coefficient of std \\
\hline$T$ & Temperature $(\mathrm{K})$ & $v$ & Poisson’s ratio \\
\hline$T_{a}$ & Ambient temperature $(\mathrm{K})$ & $\mu$ & Mean of strain \\
\hline$s$ & Slip direction & $\varepsilon_{0}$ & Surface emissivity \\
\hline std & Standard deviation & $\sigma_{0}$ & Boltzmann constant $\left(\mathrm{W} / \mathrm{m}^{2} \cdot \mathrm{K}^{4}\right)$ \\
\hline$V_{k}$ & Internal variables & $\dot{\gamma}$ & Entropy generation rate $\left(\mathrm{MJ} / \mathrm{m}^{3}\right.$.cycle $)$ \\
\hline
\end{tabular}

\section{Introduction}

Mechanical fatigue is the most damaging type of material degradation. It is responsible for $80-90 \%$ of the related failures [1], making the study of the fatigue performance and the design of fatigue-resistant metals crucially important [2-6]. Rich volumes of literature offer different theoretical [7-9] and experimental [6, 10] approaches to predict fatigue life, among which 
microstructure-sensitive and thermodynamically-based models are becoming widespread [11-13]. Importantly, recent crystal-plasticity models show a strong correlation between energy dissipation and crystalline deformation and call for further development of models that can effectively treat microstructure-sensitive materials $[14,15]$.

Deterministic or probabilistic microstructure-sensitive approaches have been developed to gain insight into the true nature of metals at micro-scale. Notable contributions include the work of Bandyopadhyay et al. [15] who used crystal plasticity finite element (CPFEM) to calculate the locally-stored microplastic strain energy density as the sum of the contribution of all the slip systems. Dislocation glide was the primary mechanism incorporated into the crystal plasticity model, and it was postulated that the accumulation of the strain energy until failure is a material property, independent of the load amplitude. Accordingly, Sangid et al. predicted fatigue lives at different strain amplitudes for 718Plus Nickel-based super alloy and verified their results by comparing to experimental measurements. Chen et al. [14] investigated the fatigue crack nucleation in Ni alloys using CPFEM and reported that the highest values of locally-stored strain energy determine the sites of crack nucleation and are more accurate in comparison with other criteria such as the density of geometrically necessary dislocations (GNDs). In another noteworthy work, Wilson et al. [12] used the method of integrated crystal plasticity eXtended Finite Element (CPXFEM) to study the behavior of locally-stored strain energy density parameter as the mechanistic driver for fatigue crack path and growth. Specifically, Wilson et al. [12] examined BCC, FCC, and HCP crystals of Ferritic Steel, Nickel Ti-6Al-4V, and Zircaloy4, respectively, and presented microstructurally-sensitive fatigue crack growth. Jirandehi and Khonsari presented a statistical method of estimating the microplastic strain energy per cycle based on monotonic tensile test and on the basis of the yielding heterogeneity of poly-crystalline metal grains [16]. A twoparameter Weibull function was implemented to account for the distribution of cyclic microplastic deformations. The estimations of microplastic strain energy per cycle were successfully verified by comparing with established thermodynamically-based experimental results. These studies consider the heterogenic nature of grain-level mechanical properties in a poly-crystalline metal and properly estimate the energy associated with cyclic deformations. However, the method offered in [16] provides a relatively simple engineering approach that yields realistic results at any scale.

Another approach for the prediction of fatigue life is to examine the thermal dissipation response of a material subjected to cyclic stress. The rationale behind the so-called thermodynamically-based model is that microplastic deformation directly manifests itself in dissipated energy that can be measured. Meneghetti [17] introduced a novel approach for quantifying the heat dissipation at steady state by measuring the rate at which a specimen cools down from its steady-state temperature upon interrupting the test. He argued that quantifying the heat loss is more representative of fatigue damage than merely considering the temperature variations. The applicability of the approach to assessing damage was verified in different works with over 140 uniaxial fatigue tests [18]. Rigon et al. [18] verified this method for the multiaxial fatigue of stainless steel 304 samples. Bayati et al. [19] investigated the heat dissipation of additively manufactured NiTi specimens under cyclic loading using an infrared (IR) camera to study and predict its fatigue properties such as the fatigue limit. Ribeiro et al. [13] used the concept 
of exergy (the maximum recoverable and useful work of a system interacting with the environment) to quantify fatigue damage irreversibility. As a result, they measured the Fracture Fatigue Entropy (FFE as introduced by Naderi et al. [20]) by measuring temperature during the fatigue test of Al 2024 samples. Basaran et al. [21-23], introduced the unified mechanics theory [21] and presented a scheme based on the relation between entropy production and accumulated damage under cyclic loading [22]. Accordingly, the unified mechanics theory was used to propose analytical and computational models for low-cycle fatigue life prediction of Ti-6Al-4V alloys [23] . Wang et al. [24] proposed a model for fatigue crack growth based on the dissipated energy at the crack tip. The energy dissipation rate at the crack tip was measured via thermography and used to estimate the fatigue crack growth rate. Using thermography, Hajshirmohammadi and Khonsari $[25,26]$ evaluated the fatigue crack propagation, proposed a relationship between the stress intensity factor and the initial slope of temperature rise at the onset of cyclic loading, and introduced an entropic formulation for evaluating the speed at which a crack grows.

Thermodynamic-base approaches are nondestructive and provide viable means for performing accelerated testing. Liakat et al. [27] presented a technique based on measuring the slope of the temperature rise in specimens with prior fatigue damage and estimated the remaining fatigue life. Rigon and Meneghetti [28] developed an engineering method for measurement of fatigue stress intensity threshold for both conventional and additively manufactured materials, with a microstructure-related length parameter incorporated to account for the effect of defects. Despite the rich volume of reported studies, the use of microstructure-sensitive strain energy in conjunction with the governing thermodynamics of micro-deformations to predict fatigue life is still lacking.

The present work proposes a fatigue life estimation method by linking the microstructurebased cyclic strain energy with the thermodynamically-based fatigue criterion. The model for the Statistical Estimation of Plastic Strain Energy (SEPSE) introduced by the authors in a recent study [16] is utilized to obtain the plastic strain energy (PSE) per cycle of low carbon steel (LCS 1018) and aluminum 7075-T6 (Al 7075-T6) specimens. The FFE for each case is estimated following the finite element (FE) simulations to obtain the steady-state temperature. What follows in section 2 is the theory of the implemented method. Section 3 provides the details of the conducted experiments to verify the results. In Section 4, additional details on the numerical method are provided. Sections 5 and 6 present the results along with related discussions, and the application of the proposed method, respectively. Finally, Section 7 is devoted to summary and concluding remarks.

\section{Theory and formulation}

\subsection{Heat transfer in a metallic medium}

Metals experience permanent deformation under cyclic loading due to the movement, interaction, and evolution of dislocations that result in heat generation and dissipation. The first law of thermodynamics for a unit control volume on the gauge section of a specimen is expressed in Eq. (1) [29].

$\frac{\partial}{\partial t}(\rho u)=\sigma: D-\nabla \cdot \vec{q}$ 
where $\sigma: D$ is the internally-generated energy due to plastic deformations, $\nabla . \vec{q}$ is the divergence of the heat flux vector, and $\frac{\partial}{\partial t}(\rho u)$ is the rate of change in specific internal energy. $\sigma$ is the applied Cauchy stress tensor on the control volume, and $D$ is the rate of deformation tensor [29]. $u$ is the internal energy, and defined as $u=\Psi+T s$ ( $\Psi$ is the Helmholtz free energy, $T$ is the temperature and $s$ is the entropy).

According to the second law of thermodynamics, written in the form of Clausius-Duhem inequality, the rate of entropy generation is always greater than or equal to zero [29].

$\rho \frac{\partial s}{\partial t}+\nabla \cdot\left(\frac{\vec{q}}{T}\right) \geq 0$

where $s$ denotes the specific entropy, $T$ is the temperature, and $\nabla \cdot\left(\frac{\vec{q}}{T}\right)=\frac{\nabla \cdot \vec{q}}{T}-q \cdot \frac{\operatorname{grad} T}{T^{2}}$. Using the Helmholtz free energy and by defining the related state variables, one can arrive at Eq. 3, knowing that for small strains, the rate of the deformation tensor $(D)$ can be replaced by the total strain rate $(\dot{\varepsilon})$.

$\dot{\gamma}=\frac{1}{T}\left(\sigma: \dot{\varepsilon}_{p}-A_{k} \dot{V}_{k}-\frac{k \nabla^{2} T}{T}\right) \geq 0$

where $\dot{\gamma}$ is the rate of entropy generation, and $A_{k}$ is the associated function with the internal variables. The terms on the right-hand-side of Eq. 3 represent the energy dissipation due to plastic deformation, non-recoverable stored energy, and heat dissipation due to conduction.

Eq. 1 can be rewritten based on the time derivative of internal energy $\left(\frac{\partial u}{\partial t}=\frac{\partial(\Psi+T s)}{\partial t}\right)$ and the related internal variables [20]. Considering the relation between entropy-Helmholtz free energy ( $s=-\frac{\partial \psi}{\partial T}$ ) and Fourier's law, the governing heat equation on a solid medium under cyclic loading can be expressed by Eq. 4.

$\rho C \dot{T}=\sigma: \dot{\varepsilon}_{p}-A_{k} \dot{V}_{k}+k \nabla^{2} T+T\left(\frac{\partial \sigma}{\partial T}: \dot{\varepsilon}_{e}+\frac{\partial A_{k}}{\partial T} \dot{V}_{k}\right)$

where $C=T \frac{\partial S}{\partial T}$. The nonrecoverable energy term $\left(A_{k} \dot{V}_{k}\right)$ in Eqs. 3 and 4 makes up 5-10\% of the entropy generation in metals and is assumed negligible, making the derivative of the internal variables function insignificant [20]. Since the temperature rise caused by the thermoelastic effect is quite small compared to the mean temperature rise [29], the governing heat equation can be expressed as in Eq. 5.

$\rho C \dot{T}=\dot{w}_{p}+k \nabla^{2} T$

where $\dot{w}_{p}=\sigma: \dot{\varepsilon}_{p}$, representing the plastic strain energy rate. Given that the plastic deformation is dominant in low-cycle fatigue, the accumulation of entropy until failure $\left(\gamma_{f}\right)$ is obtained from Eq. 3. 
$\gamma_{f}=\int_{0}^{t_{f}} \dot{\gamma} d t=\int_{0}^{t_{f}} \frac{\dot{w}_{p}}{T} d t$

where $t_{f}$ is time to failure. According to Naderi et al. [20], the summation of thermodynamic entropy production over the life span of metal under cyclic loading (Eq. 6) can be considered as a material property called the fracture fatigue entropy (FFE). This parameter is shown to be independent of geometry, load and frequency. Mehdizadeh and Khonsari [30] measured the dissipated energy rate due to plastic deformations based on the initial slope of temperature rise at the beginning of a cyclic test $\left(\dot{w}_{p}=\left.\rho c_{p} R_{\theta}\right|_{t=0}\right)$.

Based on Eq. $6, \dot{w}_{p}$ and the steady-state temperature $T$ are required to estimate the FFE. Research shows that metal's temperature subjected to cyclic loading evolves in three phases [30, 31]. In Phase I, there is an initial rise due to the increase in dislocation density and multiplication. Next, in Phase II, the temperature stabilizes and the specimen operates in this phase for a major portion of its life. Eventually, in Phase III, the metal experiences a rapid jump in temperature until it fractures [31]. To predict the steady-state temperature, Eq. 5 must be solved over the entire body of the specimen with the appropriate boundary conditions.

\subsection{Microstructure-sensitive plastic strain energy}

Polycrystalline metals exhibit region-specific mechanical characteristics, such as yield limit and plastic deformations under cyclic loading (See illustration in Fig. 1). To obtain microplastic strain energy accumulation in the microstructure, the contribution of each element needs to be identified and summed to obtain the total value.

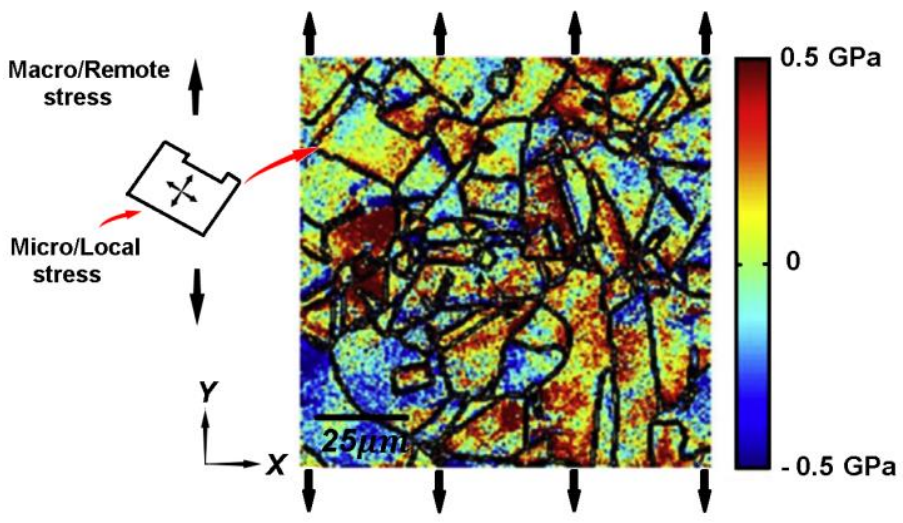

(a)

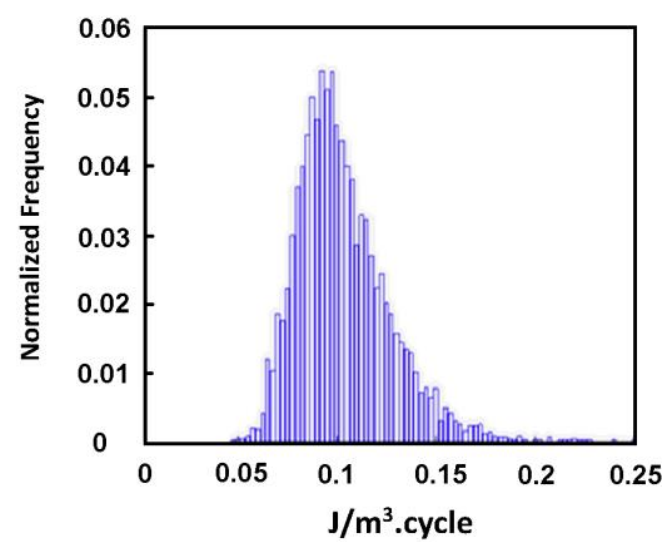

(b)

Figure 1. Example of heterogeneity inside and outside polycrystalline copper grains under loading; a) Residual shear stress distribution is obtained via HR-EBSD and after 6\% uniaxial straining. The probability distribution of the micro-residual stress components follows a normal/Gaussian distribution. b) The probability distribution of locally-stored plastic strain energy spots under $2 \%$ strain amplitude and after the $10^{\text {th }}$ cycle of uniaxial fatigue loading. Both of the Figures are taken and redrawn from the study by Wan et al. [32]. 
The following two-parameter Weibull probability function can be used to obtain the distribution of micro-plastic strains under any cyclic load amplitude from the monotonic stressstrain curve of a metal [16].

$f(x)=\frac{\alpha \times s t d}{\mu}\left(\frac{x}{\mu}\right)^{\alpha \times s t d-1} e^{-(x / \mu)^{\alpha \times s t d}}$

where std is the standard deviation of the strain data $(x), \mu$ the average of the strains, and $\alpha$ is a coefficient determined at the point where $\frac{\partial^{2} P S E}{\partial \alpha^{2}}=0$. A second probability function is incorporated to account for different crystallographic directions. According to von Mises, at least 5 independent slip systems need to activate to preserve the metal's shape continuity under loading [33]. Knowing the degrees of freedom for each grain with $s$ slip direction is $2 s$ [34], the probability that considers this criteria is expressed by Eq. 8 [35].

$P(s)=\sum_{i=1}^{5} \frac{1}{2 s-(i-1)}$

where $s$ is the number of slip systems and determined based on whether the crystalline microstructure is FFC or BCC. Accordingly, if the metal contains $k$ plastically-deformed elements, the PSE per cycle of at each cyclic load amplitude can be determined via Eq. 9.

$E_{c}=\sum_{j=1}^{k} 2 K \frac{\alpha \times s t d}{\mu^{\alpha \times s t d}}\left(\sum_{i=1}^{5} \frac{1}{2 s-(i-1)}\right) \int_{Y}^{\epsilon_{k}} \varepsilon_{p}^{n+\alpha \times s t d-1} e^{-\left({ }^{\varepsilon_{p}} / \mu\right)^{\alpha \times s t d}} d \varepsilon_{p}$

where $K$ is the strain-hardening coefficient, $Y$ represents the true yield point where the stress-strain relationship turns nonlinear, and $\epsilon_{k}$ stands for the strain of the $k$ element.

To obtain the proper value of $\alpha$, two criteria are introduced. First, the mean of the strain values of the elements should be equal to the applied cyclic strain value. Accordingly, the proper $\alpha$ value should match the peak of Weibull distribution with the mean of the applied cyclic strain, as shown in Fig. 2. Second, a study of the variations of predicted PSE values with $\alpha$ indicates that there is a final stabilized region preceded by a change in the convexity of the curve [16]. Therefore, referring to Fig. 2, the appropriate value for $\alpha$ is where the second derivative of PSE curve with respect to $\alpha$ becomes zero or the convexity flips direction $\left(\frac{\partial^{2} P S E}{\partial \alpha^{2}}=0\right)$. 

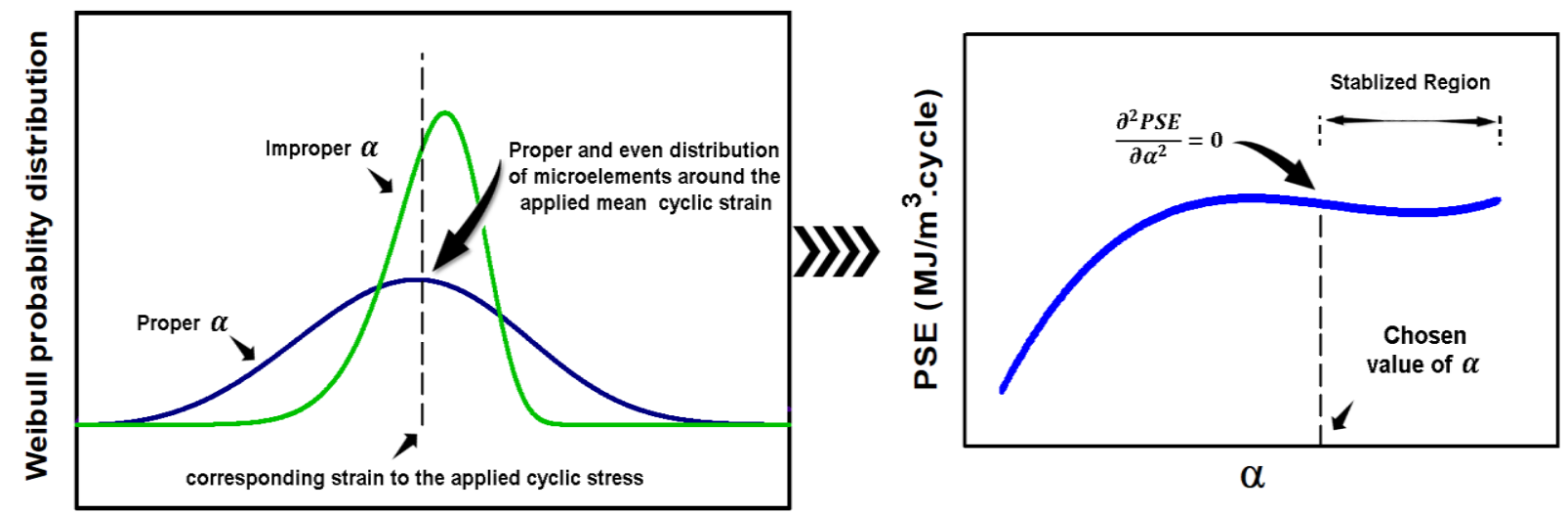

Strain

Figure 2. Weibull distribution around the mean of the micro-strain values and PSE- $\alpha$ variations as the two standards for determining the proper $\alpha$

\section{Numerical simulation}

To predict the temperature distribution of the specimens under cyclical loading, the basic finite element package (FE) included in Wolfram Mathematica software is used to solve Eq. 5. Since the specimens are symmetric with respect to the longitudinal axis, a 2D domain of half of the specimen as shown in Fig. 3 is chosen for the analysis and meshed with $2 \mathrm{D}$ and triangular elements [36]. Mesh is refined to ensure mesh-independent results. Table 1 indicates the sensitivity of steady state temperature calculations with respect to the number of elements.

Table 1. variations of the steady state temperature with change in the number of elements

\begin{tabular}{|c|c|c|}
\hline \multirow{2}{*}{$\begin{array}{c}\text { Total number of } \\
\text { elements }\end{array}$} & \multicolumn{2}{|c|}{$T_{s s}(\mathbf{k})$} \\
\cline { 2 - 3 } & $\begin{array}{c}\text { AL 7075-T6 } \\
\text { (450 MPa) }\end{array}$ & $\begin{array}{c}\text { CS 1018 } \\
\text { (430 MPa) }\end{array}$ \\
\hline $\mathbf{3 3 2}$ & 297.0 & 317.8 \\
\hline $\mathbf{4 8 5}$ & 297.1 & 317.9 \\
\hline $\mathbf{6 1 0}$ & 297.1 & 317.9 \\
\hline
\end{tabular}

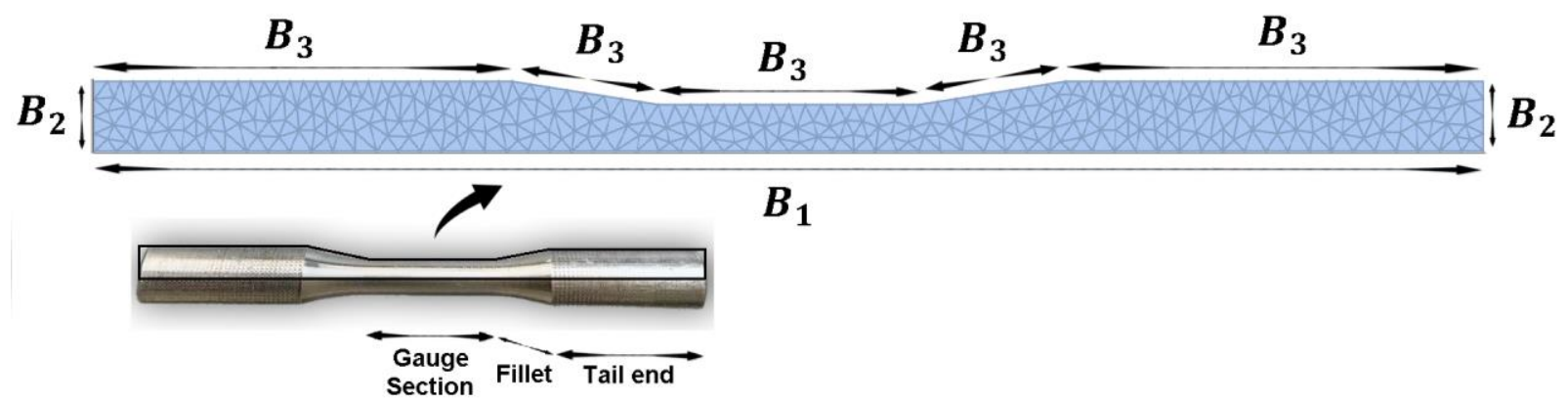

Figure 3. The test specimen and the 2D FEM model of half of the specimen. 
In general, the heat loss from the surface of the gauge section can involve both convection and radiation. The boundary condition in Eq. 10 is applied to the gauge section, two fillet regions and two peripheral areas of the cylindrical tail-ends of the specimen (denoted by $B_{3}$ in Fig. 3).

$\vec{n} \cdot(-k \nabla T(t, x))=\overbrace{h\left(T-T_{a}\right)}^{\text {convective }}+\overbrace{\sigma_{0} \varepsilon_{0}\left(T^{4}-T_{a}{ }^{4}\right)}^{\text {radiative }}$

where $\vec{n}$ is the normal vector to the gauge section surface and thus $\vec{n} .(-k \nabla T(t, x))$ is the heat flux in the direction of normal to the boundary by implementing Fourier's law. $h$ is the heat transfer coefficient and is assumed to be $25 \mathrm{~W} / \mathrm{m}^{2} . \mathrm{K}$. The Boltzmann and thermal emissivity constants (denoted by $\sigma_{0}$ and $\left.\varepsilon_{0}\right) 5.67 \times 10^{-18}$ and 0.93 , respectively. The ambient temperature was around $22{ }^{\circ} \mathrm{C}$ during the experiments.

Based on the observations during experiments the two cross-sectional areas of the cylindrical tail-ends stay almost close to the ambient temperature (with minimal changes) throughout the experiment due to their distance from the gauge section as the main source of heat dissipation. Hence, constant temperature $\left(22^{\circ} \mathrm{C}\right)$ via Dirichlet condition is applied to the boundaries denoted by $B_{2}$ in Fig. 3. lastly, $B_{1}$ is associated with a symmetric boundary condition, where the heat flow across the boundary is zero (thermally insulated), and mirror symmetry is applied along the longitudinal axis.

\section{Experimental}

A servo-hydraulic fatigue apparatus is used to perform uniaxial tension-compression experiments. The apparatus can apply up to $50 \mathrm{kN}$ axial and $2 \mathrm{kN} . \mathrm{m}$ torque loading. Cylindrical dog-bone specimens are designed based on ASTM E 466-15 standard (Fig. 4), and the tail-ends are gripped in the bottom and top grips of the machine during each experiment. To apply any cyclic load, one must fix the top grip assembly and allow the bottom one to actuates vertically.

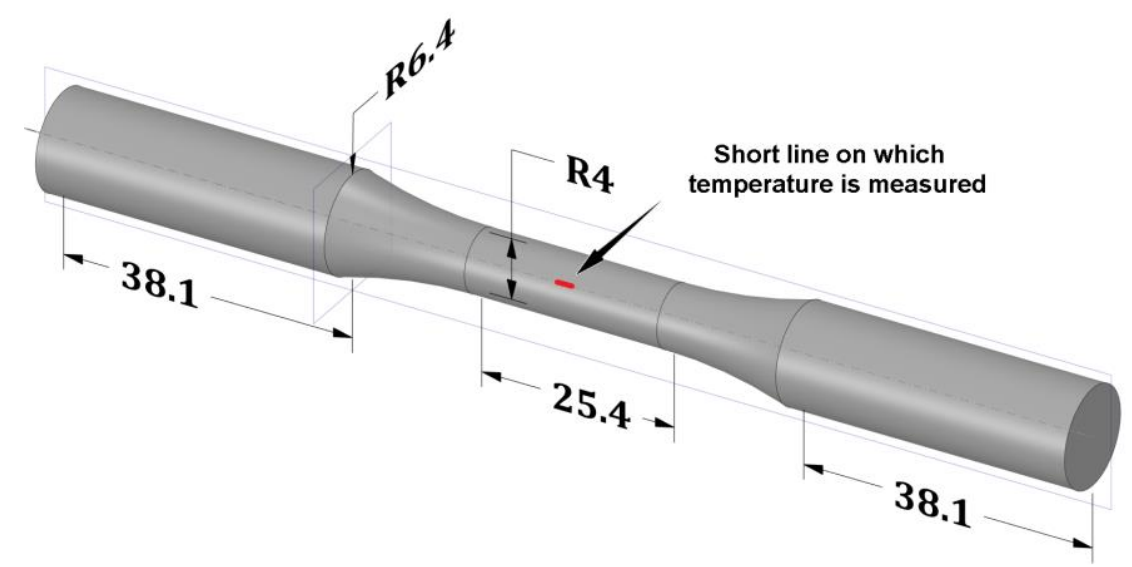

Figure 4. Cylindrical dog-bone specimen design based on ASTM E 466-15 (all dimensions in mm)

Aluminum 7075-T6 (Al) and Low Carbon Steel 1018 (LCS) specimens with the compositions presented in Tables 2 and 3 are tested at different fully reversed $(R=-1)$ cyclic load amplitudes and under $10 \mathrm{~Hz}$ Frequency. In addition, an infrared camera (MIKRON M7500) is used 
to record the surface temperature variations of the specimens during the test, to be used for the verification of the temperature results via FEM. The specimens gauge sections were coated with a thin layer of black paint to improve thermal emissivity for IR measurements. Temperature values on a line in the middle of the gauge section (the critical region where the specimens fail) are averaged and reported (See Fig. 4).

Table 2. The chemical composition of LCS

\begin{tabular}{|c|c|c|c|c|c|}
\hline Material & C & Fe & Mn & S & P \\
\hline LCS & $0.14-0.2$ & $98.81-99.26$ & $0.6-0.9$ & $0.05 \max$ & $0.04 \max$ \\
\hline
\end{tabular}

Table 3. The chemical composition of Al 7075-T6

\begin{tabular}{|c|c|c|c|c|c|c|c|c|c|c|c|c|}
\hline Material & Al & Cr & $\mathbf{C u}$ & $\mathbf{F e}$ & $\mathbf{M g}$ & $\mathbf{M n}$ & $\mathbf{N i}$ & $\mathbf{S i}$ & $\mathbf{T i}$ & $\mathbf{Z n}$ & $\mathbf{Z r}$ & Other \\
\hline Al 7075- & $87.1-$ & $0.18-$ & $1.2-$ & $0-$ & $2.1-$ & $0-$ & $0-$ & $0-0.4$ & $0-0.2$ & $5.1-$ & $0-$ & $0-0.15$ \\
T6 & 91.42 & 0.287 & 2.0 & 0.5 & 2.9 & 0.3 & $<0.01$ & & & 6.1 & $<0.05$ & \\
\hline
\end{tabular}

Monotonic tensile tests are performed based on ASTM E8/E8M standard. Table 4 shows the tensile and physical properties of the tested materials.

Table 4. Mechanical properties of the materials

\begin{tabular}{|c|c|c|c|c|c|}
\hline \multirow{2}{*}{ Material } & \multicolumn{2}{|c|}{ Physical properties } & \multicolumn{3}{c|}{ Tensile strength } \\
\cline { 2 - 6 } & Density & $\begin{array}{c}\text { Specific heat } \\
\text { capacity }\left(C_{p}\right)\end{array}$ & $\begin{array}{c}\text { Ultimate } \\
\text { Strength }\left(\sigma_{u}\right)\end{array}$ & $\begin{array}{c}0.2 \% \text { Yield } \\
\text { strength }\left(\sigma_{y}\right)\end{array}$ & $\begin{array}{c}\text { Elastic } \\
\text { modulus }(E)\end{array}$ \\
\cline { 2 - 6 } & $\mathrm{Kg} / \mathrm{m}^{3}$ & $\mathrm{~J} / \mathrm{Kg} . \mathrm{K}$ & $\mathrm{MPa}$ & $\mathrm{MPa}$ & $\mathrm{GPa}$ \\
\hline LCS & 7850 & 486 & 510 & 450 & 205 \\
\hline Al 7075-T6 & 2810 & 960 & 567 & 480 & 70 \\
\hline
\end{tabular}

\section{Results and discussion}

\subsection{Temperature calculation}

Research reveals that in Phase II of the temperature evolution the average value of PSE per cycle is fairly constant and remains stable for most of the specimen's fatigue life [15, 37, 38]. In Phase III, which typically accounts for much less than 10 percent of the fatigue life, macro-cracks are formed, and temperature increases rapidly due to the associated high dissipative energy [20]. Therefore, considering a constant per cycle of energy in the analysis is a viable assumption.

Statistically-estimated values of PSE per cycle via SEPSE (as reported in [16]) are used as the plastic strain energy rate $\left(\dot{w}_{p}\right)$ or intrinsic heat dissipation term in Eq. 5 . Knowing the parameters for the internal heat generation $(\rho C \dot{T})$ and heat transfer through conduction $\left(k \nabla^{2} T\right)$, the numerical FE method described in Section 4 are used to solve Eq. 5 over the domain in Fig. 3. 
The evolution of temperature at the point where the temperature is maximum is plotted and compared against the experimental curves obtained via the IR camera. Fig. 5 shows the calculations of temperature evolution in phases I and II of LCS 1018 and Al 7075-T6 specimens' lives at $\sigma=430 \mathrm{MPa}$ and $\sigma=450 \mathrm{MPa}$, respectively. The displayed temperature curve via the IR camera are postprocessed to eliminate the measurement noise.

The area enclosed within an experimentally-measured hysteresis stress-strain loop during cyclic loading is a direct measure of the amount of accumulated PSE in the low-cycle fatigue regime, and directly manifests itself in the evolution of temperature measured via the IR Camera [39]. The SEPSE estimates are verified against the experimentally measured values of PSE [16]. However, minor differences exist between the two models due to the probabilistic nature of the SEPSE method. Therefore, the calculated temperature via FEM indicates minor variations from the IR camera temperature as it inputs the plastic strain energy rate from SEPSE. In Fig. 5-a, the temperature curve via the FEM is slightly more than the experimental surface temperature evolution curve via the IR camera. This is because the SEPSE estimate is higher than the hysteresis loop energy. The estimated temperature curve via FEM is below the experimental curve in Fig. 5$\mathrm{b}$ due to the fact that the statistically-calculated PSE value is less than the hysteresis energy.

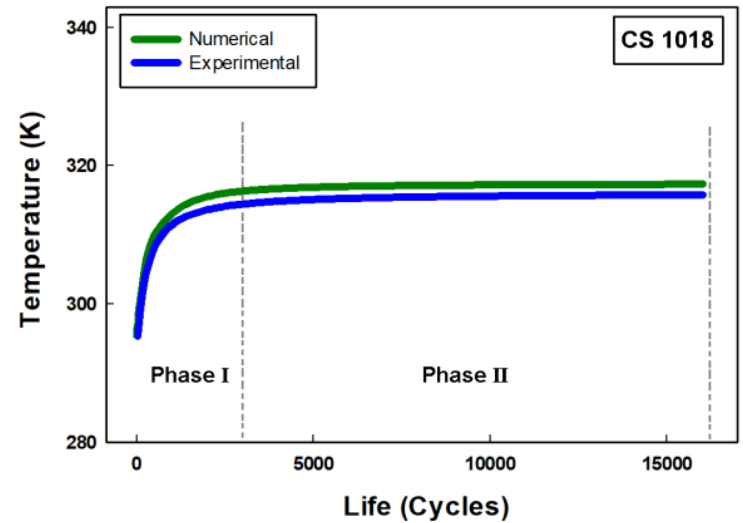

(a)

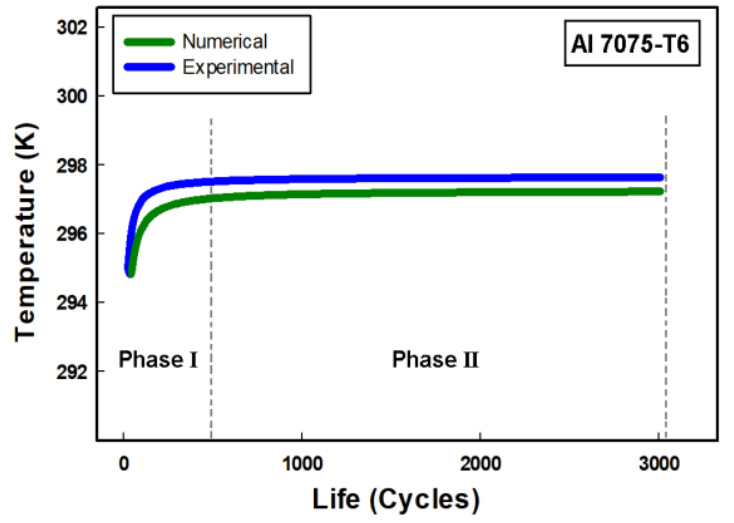

(b)

Figure 5. Temperature evolution of a) LCS 1018 under $\sigma=430 \mathrm{MPa}$, b) Al 7075-T6 under $\sigma=450 \mathrm{MPa}$

The experimental and numerical temperature distribution contours are compared in Figs. 6 and 7 to gain more insight. In general, good correspondence is seen between the size of the critical region in the temperature profiles with the IR camera and the simulations. Figs. $6 \mathrm{a}$ and $6 \mathrm{~b}$ show LCS 1018 specimens under $\sigma=430 \mathrm{MPa}$ and $415 \mathrm{MPa}$, respectively. In this case, the length of the isothermal band with maximum temperature decreases with reducing the load amplitude $\left(L_{2}<\right.$ $L_{1}$ ). This occurs since the size of the locally-stored energy density due to microstructural plastic deformations decreases with decreasing the load amplitude [14]. At a low load amplitude ( $\sigma=$ $415 \mathrm{MPa}$ ), the length of the minimum isothermal band at the tail ends of the specimen is increased $\left(L_{2}^{\prime}>L_{1}^{\prime}\right)$. This corresponds to the experimental observation of having minimal and negligible temperature variations on the cross-sectional area of the tail ends as described in Section 3. 


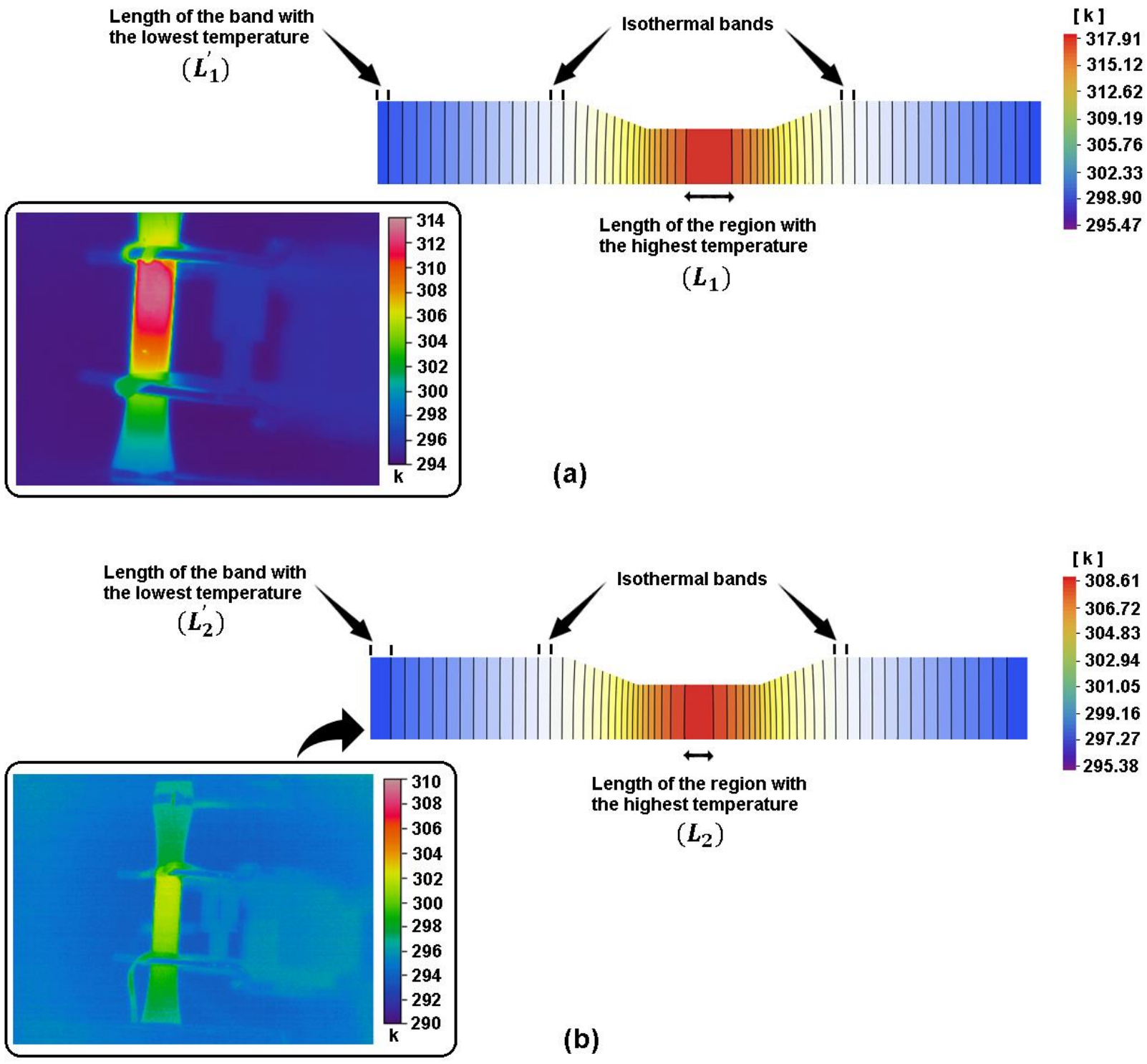

Figure 6. Experimental vs numerical temperature distribution contour of LCS 1018 specimens under a) $\sigma=430 \mathrm{MPa}$ and b) $\sigma=415 \mathrm{MPa}$

In the case of Al 7075-T6 (Fig. 7), the length of the region with maximum critical isothermal band decreases with decreasing the load amplitude similar to that observed in the case of LCS $1018\left(L_{4}<L_{3}\right)$. Similarly, this can be associated with the decrease in the local energy dissipation sites in the microstructure upon decreasing the load amplitude [40]. In addition, the length of the isothermal band with the minimum temperature and neighboring the cross-sectional area of the tail ends increases at the lower load amplitude $\left(L_{4}^{\prime}>L_{3}^{\prime}\right)$. 


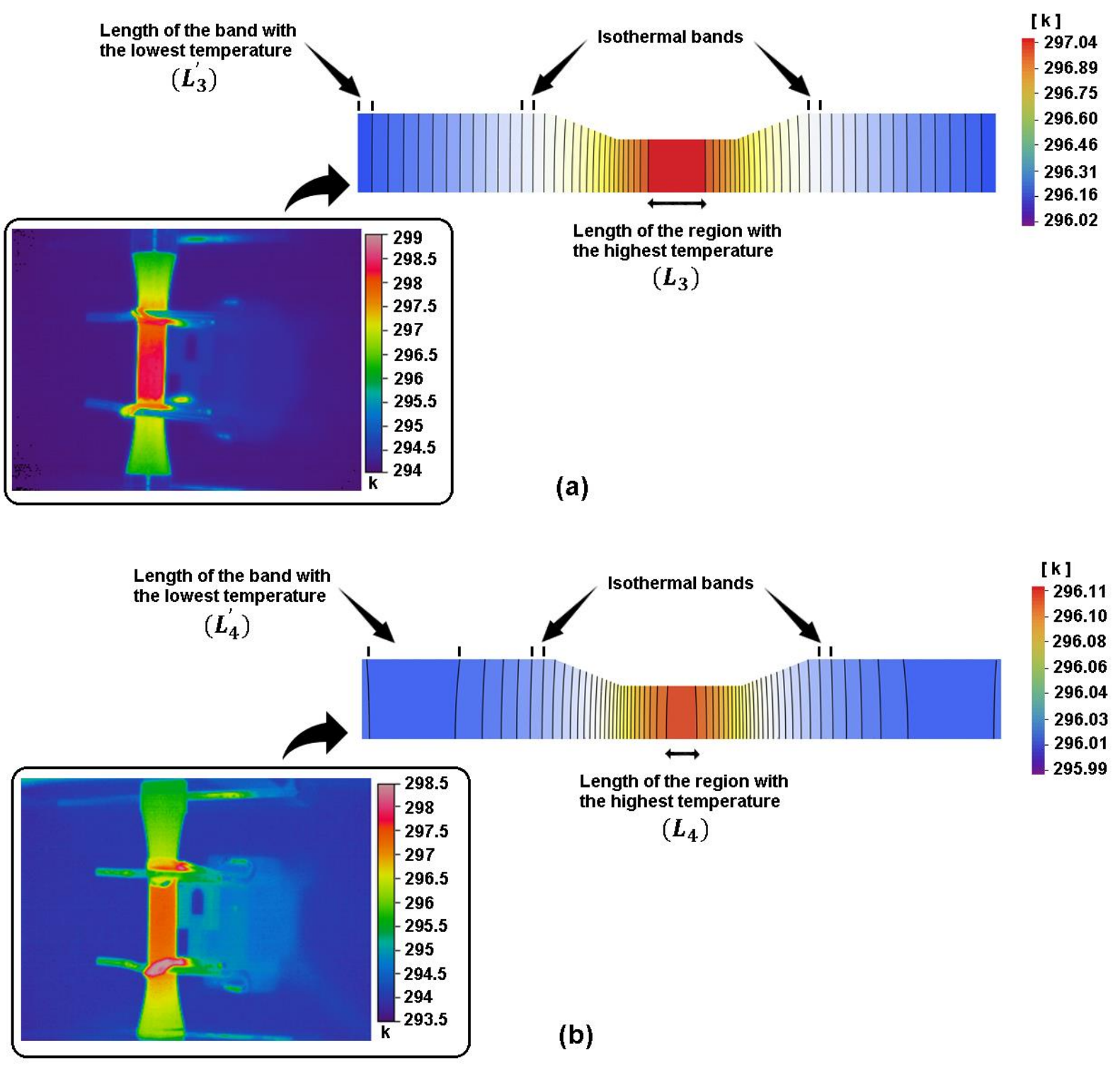

Figure 7. Experimental vs numerical temperature distribution contour of Al 7075-T6 specimens under a) $\sigma=450 \mathrm{MPa}$ and b) $\sigma=360 \mathrm{MPa}$

In ref. [16] the results of PSE per cycle is estimated for LCS 1018 and Al 7075-T6 at $\sigma=$ $415,430,440,450 \mathrm{MPa}$ and $\sigma=325,350,360$, and $450 \mathrm{MPa}$ for fully-reversed $(R=-1)$ load amplitudes, respectively. Accordingly, the steady-state temperature of LCS 1018 and Al 7075-T6 under the load amplitudes is estimated. In summary, first, the PSE per cycle is obtained for different load amplitudes via SEPSE. Then, the FE method, as described in Section 4, is used to obtain the temperature distribution along the 2D surface of half of the specimen. Figs. 5-7 further corroborate the reflection of microscale behavior into the temperature predictions by demonstrating good agreement between FEM and the experimental results. The variations of the temperature from the critical band in the gauge section is plotted as a function time, and the steady- 
state temperature is obtained. Fig. 8 illustrates the summary of the procedure to obtain the steadystate temperatures for LCS 1018.

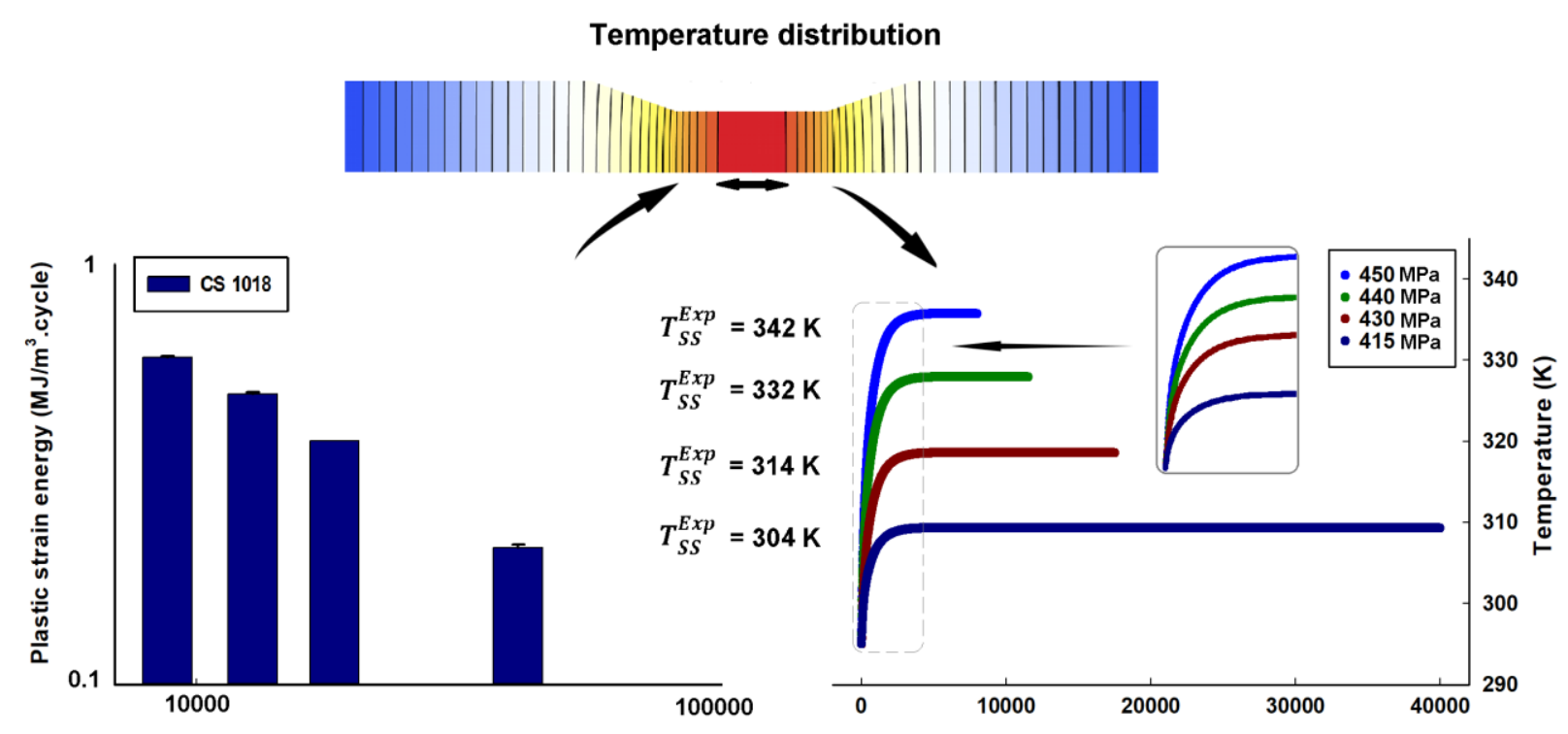

Figure 8. Diagram of the steps to obtain steady state temperature via the proposed numerical method. The displayed life in the temperature-life graph includes Phases I and II, while the PSE-Life curve shows the failure life in each case. To wit, the failure life in one example is around 18300 cycles, while Phase II ends at around 17500 cycles.

\subsection{Rapid estimation of fracture fatigue entropy}

The fracture fatigue entropy (FFE) has been established as a thermodynamic-base fatigue damage indicator. Given the direct relation between the thermal cyclic energy and the sites of crack nucleation, a microstructure-sensitive and FFE-based method of fatigue life estimation is proposed in this section. To estimate the FFE, the PSE values via SEPSE and the analytically-calculated steady state temperature is used in Eq. 6 for each case of loading with the two materials. Although the range of steady-state temperature variations along the gauge section is not as significant to produce largely different FFE values via Eq. 6, the maximum isothermal band is used in the calculations, since the mid-region is usually the expected failure location both empirically and based on ASTM E 466-15 for fatigue specimens (in case of materials with lower thermal conductivity, the generated heat due to plastic deformations is shown to be even more confined to the specimen mid-section [31]). Fig. 9 shows the predicted FFE values via the analytical method and the experimental one. In the experimental method an IR camera is used to measure the initial slope of temperature rise $\left(R_{\theta}=\frac{d T}{d t}\right)$ [30]. Then, PSE is calculated based on the relationship between $R_{\theta}$ and the dissipated energy rate $\left(\dot{w}_{p}=\left.\rho c_{p} R_{\theta}\right|_{t=0}\right)$ [30]. Using the measured steadystate temperature from the IR camera and Eq. 6 [16], FFE is obtained experimentally. In both 
cases, the average estimated value is approximately $21 \mathrm{MJ} / \mathrm{m}^{3} . \mathrm{K}$. The dashed and dashed-dotted lines show the upper and lower bands in the estimations via the experimental and the proposed analytical method, respectively. In the case of AL 7075-T6 and as demonstrated by Fig. 10, the average estimated value with the experimental method is around $0.7 \mathrm{MJ} / \mathrm{m}^{3} . \mathrm{K}$ versus an average of approximately 0.6 with the analytical method. In addition, the lower and upper bands are close to each other in both of the cases, thus providing comparable ranges of FFE values.

The permanent movement, reorientation, and agglomeration of dislocations result in the reorganization of polycrystalline microstructure and lead to plastic deformations. Munier et al. [41], tracked the evolution of persistent slip bands in several grades of steel and correlated that with the dissipated heat under cyclic loading. The so-called dark-spots evolve on the surface and depth of the metals as a result of the formation of slip bands. Moreover, their population versus the area they occupy was shown to follow a Weibull distribution. Munier et al, postulate that these locations are the hotspots where the local heat dissipation under cyclic loading occurs. The SEPSE method considers the contribution of micro-scale units (microelements, grains, or sub-grains) to the generation of PSE. Then the PSE manifests in the form of dissipated heat under cyclic loading. Accordingly, the SEPSE-based estimated FFE in this work via Eq. 5 can be interpreted as the sum of the entropy generation of the microelements of SEPSE or the dark-spots of Munier et al. over the duration of the experiment until failure. Therefore, the FFE estimation procedure in this work is cognizant of the polycrystalline microstructure in contrast with the available experimental method.

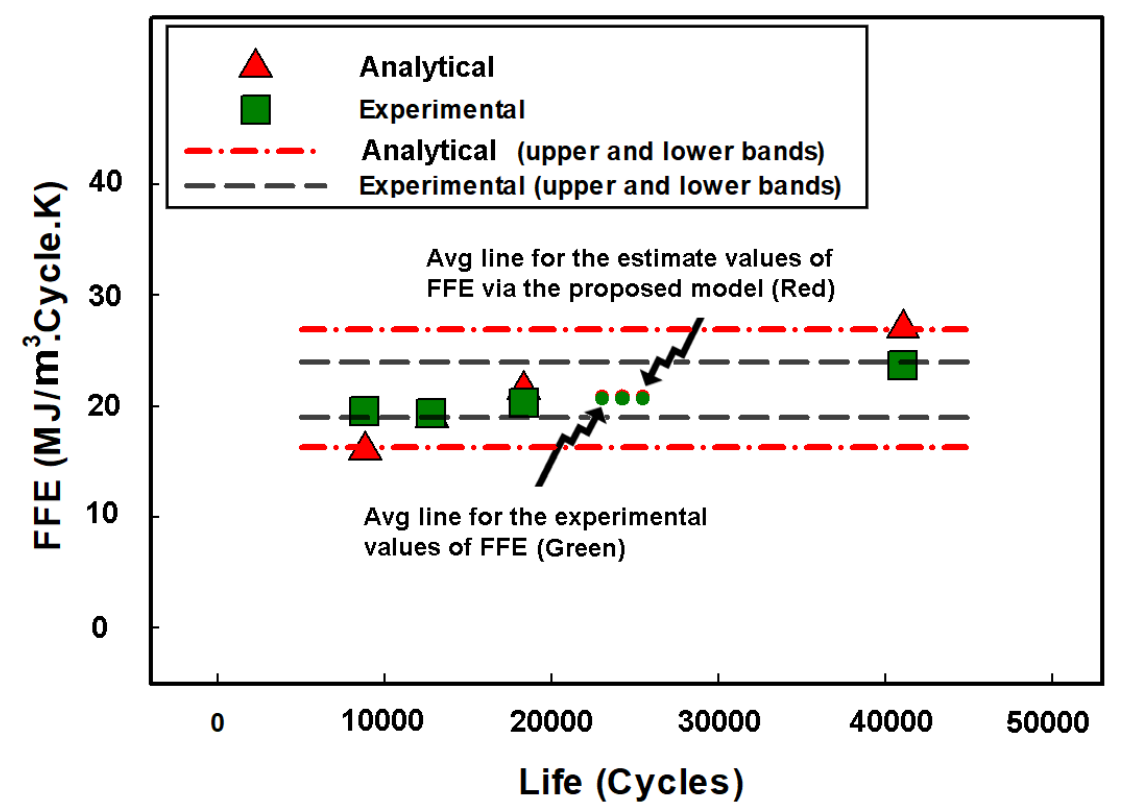

Figure 9. Estimations of FFE via the analytical and experimental methods for LCS 1018 


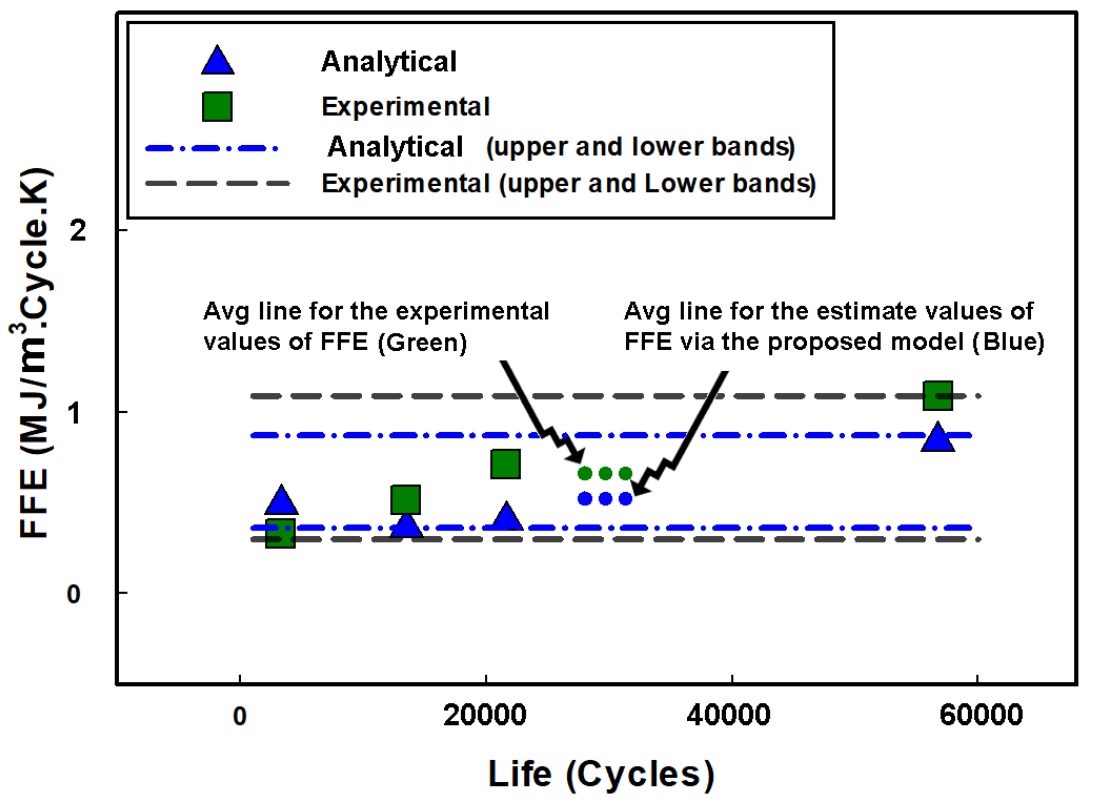

Figure 10. Estimations of FFE via the analytical and experimental methods for Al 7075-T6

Having estimated FFE via the analytical model, we now proceed to predict the fatigue life of other cyclic load amplitudes and compare with the experimental data Fig. 11 shows the results for both types of materials tested. The continuous line shows the mean regression of the data and follows the bisector of the coordinates plane, which is an indication of a good correlation between the proposed method and the experimental results. The dashed lines show the endpoints for the 99\% confidence intervals in the experimental-predicted datapoints and is a measure of the level of confidence in the predicted regression of the points.

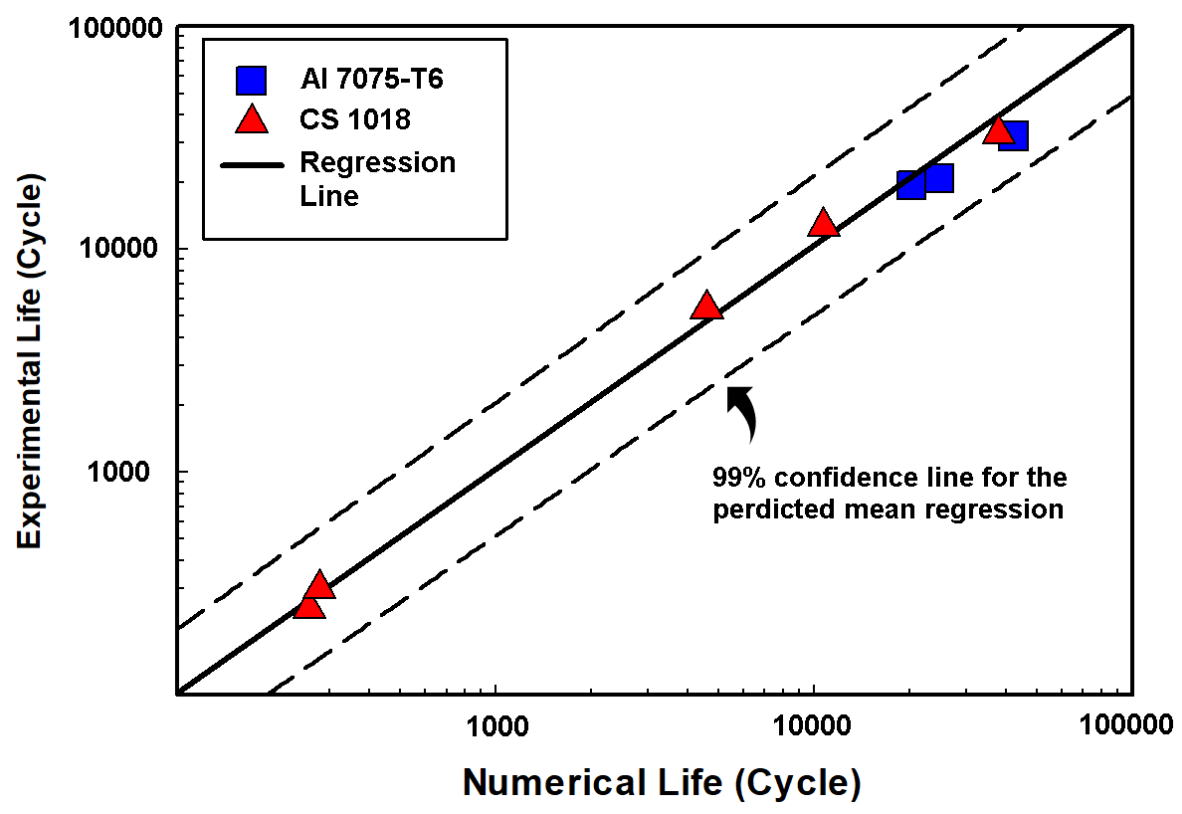

Figure 11. Experimental fatigue life of Al 7075-T6 and LCS 1018 specimens at different cyclic load amplitudes vs the predictions via the proposed model. 
Results presented in Table 6 provide further insight into the reliability of the proposed model. The table shows the stress levels, PSE per cycle predictions via SEPSE method, the numerically-estimated temperatures along with the experimental and predicted fatigue lives. A negative error value shows that the predictions are above the experimental fatigue lives and the positive errors indicate that the predicted lives are lower than the experimental ones. The highest error in the estimated lives is $23.9 \%$ and the lowest error in life estimation is $4.8 \%$. The average error values for Al 7075-T6 and LCS 1018 are 12.5\% and 15\%, which means the overall error of predictions via the proposed method is around $13.7 \%$. Given the statistical nature of the SEPSE method and the proposed numerical method in this work, the errors in life prediction are satisfactory.

Table 6. Experimental and predicted results for AL 7075-T6 and LCS 1018

\begin{tabular}{|c|c|c|c|c|c|c|}
\hline Materials & $\begin{array}{c}\text { Stress } \\
\text { amplitude } \\
(\mathbf{M P a})\end{array}$ & $\begin{array}{c}\boldsymbol{W}_{\boldsymbol{p} \text { (SEPSE) }} \\
\left(\mathbf{M J} / \mathbf{m}^{\mathbf{3}} \cdot \mathbf{. c y c l e}\right)\end{array}$ & $\begin{array}{c}\boldsymbol{T}_{\boldsymbol{S}(\boldsymbol{F E M})} \\
(\mathbf{K})\end{array}$ & $\begin{array}{c}\text { Experimental } \\
\text { Life (Cycles) }\end{array}$ & $\begin{array}{c}\text { Predicted } \\
\text { Life } \\
(\mathbf{C y c l e s})\end{array}$ & $\begin{array}{c}\text { Error } \\
(\%)\end{array}$ \\
\hline \multirow{4}{*}{ Al 7075-T6 } & 515 & 0.667 & 310.1 & 260 & 243 & 6.5 \\
\cline { 2 - 7 } & 510 & 0.539 & 307.6 & 280 & 299 & -6.8 \\
\cline { 2 - 7 } & 420 & 0.0287 & 296.3 & 4600 & 5405 & -17.5 \\
\cline { 2 - 7 } & 375 & 0.0122 & 296.1 & 10700 & 12672 & -18.4 \\
\cline { 2 - 7 } & 330 & 0.0047 & 295.9 & 38000 & 32859 & 13.5 \\
\hline CS 1018 & 425 & 0.345 & 317.2 & 20300 & 19312 & 4.8 \\
\cline { 2 - 7 } & 420 & 0.321 & 316.6 & 24800 & 20715 & 16.5 \\
\cline { 2 - 7 } & 410 & 0.201 & 308.5 & 42300 & 32175 & 23.9 \\
\hline
\end{tabular}

\section{Application}

The method presented provides a viable approach to fatigue life prediction and simplifies the requirements of fatigue testing of metal by eliminating the use of an extensometer or IR camera at any point in the procedure. In summary, a monotonic tensile test has to be done to obtain an accurate stress-strain curve and the related properties of metal for the purpose of calculating the PSE per cycle for any arbitrary cyclic load amplitude. The scheme for performing this part is given in section 2.2 based on a recent microstructure-sensitive model by the authors known as SESPE. Then, a minimum of 4 cyclic tests has to be conducted only to obtain fatigue failure lives. Using the PSE values from SEPSE, the steady-state temperature of the specimen can be predicted via FE simulations. Finally, the FFE is estimated, and life for any other cyclic load amplitude can be predicted. Applying the proposed framework to high-cycle fatigue requires more experiments and assessment. The following shows a flowchart of the presented method, accordingly.
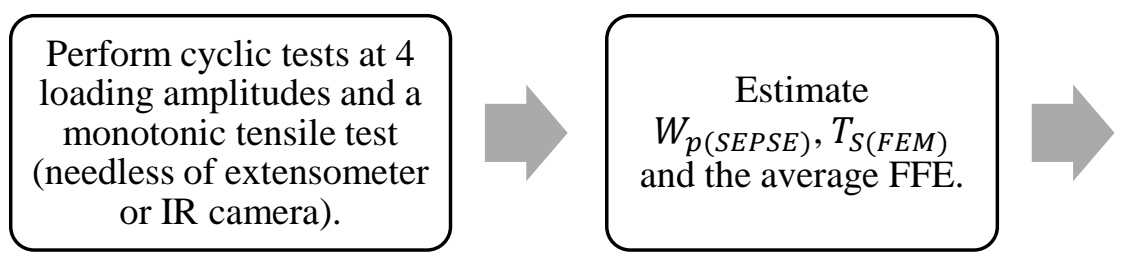
Use Eq. 6 to estimate fatigue life at any arbitrary load amplitude.




\section{Conclusions}

A method for the fatigue life estimation of metals is presented based on a microstructuresensitive estimation of plastic strain energy per cycle. A statistical method for the estimation of plastic strain energy (SEPSE) is used to calculate the dissipated energy of fatigue, and the steady state surface temperature of the specimens is obtained via the developed FE model, accordingly. FFE Al 7075-T6 and LCS 1018 samples is estimated as a fatigue index, and failure life is predicted.

The comparison of temperature vs. time evolution curve in phases I and II show good agreement with the measured contour using an IR camera during the experiments. The FE results indicate that the size of the maximum temperature isothermal band in the gauge section increases with increasing the load amplitude. The observed is consistent with experiments and is due to the added size of hotspots at high cyclic load amplitudes.

The predicted FFE values of each metal (a material property) via the proposed and the original method match, which suggests that the presented method is reliable for prediction of fatigue life.

\section{References}

[1] X. Ye, Y. Su, J. Han, A state-of-the-art review on fatigue life assessment of steel bridges, Mathematical Problems in Engineering 2014 (2014) https://doi.org/10.1155/2014/956473.

[2] G. Meneghetti, D. Rigon, D. Cozzi, W. Waldhauser, M. Dabalà, Influence of build orientation on static and axial fatigue properties of maraging steel specimens produced by additive manufacturing, Procedia Structural Integrity 7 (2017) 149-157.

[3] M. Katancik, S. Mirzababaei, M. Ghayoor, S. Pasebani, Selective laser melting and tempering of H13 tool steel for rapid tooling applications, Journal of Alloys and Compounds (2020) 156319.

[4] C. Zeng, B. Zhang, A.H. Ettefagh, H. Wen, H. Yao, W. Meng, S. Guo, Mechanical, thermal, and corrosion properties of $\mathrm{Cu}$-10Sn alloy prepared by laser-powder-bed-fusion additive manufacturing, Additive Manufacturing 35 (2020) 101411.

[5] M. Alishahi, S. Mirzaei, P. Souček, L. Zábranský, V. Buršíková, M. Stupavská, V. Peřina, K. Balázsi, Z. Czigány, P. Vašina, Evolution of structure and mechanical properties of hard yet fracture resistant WB-C coatings with varying C/W ratio, Surface and Coatings Technology 340 (2018) 103-111.

[6] M. Mohajeri, B. Haghgouyan, H. Castaneda, D.C. Lagoudas, Nickel titanium alloy failure analysis under thermal cycling and mechanical loading: A preliminary study, arXiv preprint arXiv:1803.01110 (2018).

[7] S.-P. Zhu, H.-Z. Huang, R. Smith, V. Ontiveros, L.-P. He, M. Modarres, Bayesian framework for probabilistic low cycle fatigue life prediction and uncertainty modeling of aircraft turbine disk alloys, Probabilistic Engineering Mechanics 34 (2013) 114-122.

[8] R. Namakian, H.M. Shodja, M. Mashayekhi, Fully enriched weight functions in mesh-free methods for the analysis of linear elastic fracture mechanics problems, Engineering Analysis with Boundary Elements 43 (2014) 1-18.

[9] A.P. Jirandehi, T. Chakherlou, A fatigue crack initiation and growth life estimation method in singlebolted connections, The Journal of Strain Analysis for Engineering Design 54(2) (2019) 79-94.

[10] A. Fatemi, L. Yang, Cumulative fatigue damage and life prediction theories: a survey of the state of the art for homogeneous materials, International journal of fatigue 20(1) (1998) 9-34.

[11] V. Prithivirajan, M.D. Sangid, Examining metrics for fatigue life predictions of additively manufactured IN718 via crystal plasticity modeling including the role of simulation volume and microstructural constraints, Materials Science and Engineering: A (2020) 139312. 
[12] D. Wilson, W. Wan, F.P. Dunne, Microstructurally-sensitive fatigue crack growth in HCP, BCC and FCC polycrystals, Journal of the Mechanics and Physics of Solids 126 (2019) 204-225.

[13] P. Ribeiro, J. Petit, L. Gallimard, Experimental determination of entropy and exergy in low cycle fatigue, International Journal of Fatigue 136 (2020) 105333.

[14] B. Chen, J. Jiang, F.P. Dunne, Is stored energy density the primary meso-scale mechanistic driver for fatigue crack nucleation?, International Journal of Plasticity 101 (2018) 213-229.

[15] R. Bandyopadhyay, V. Prithivirajan, A.D. Peralta, M.D. Sangid, Microstructure-sensitive critical plastic strain energy density criterion for fatigue life prediction across various loading regimes, Proceedings of the Royal Society A 476(2236) (2020) 20190766.

[16] A.P. Jirandehi, M. Khonsari, On the determination of cyclic plastic strain energy with the provision for microplasticity, International Journal of Fatigue 142 (2020) 105966.

[17] G. Meneghetti, Analysis of the fatigue strength of a stainless steel based on the energy dissipation, International journal of fatigue 29(1) (2007) 81-94.

[18] D. Rigon, V. Formilan, G. Meneghetti, Analysis of the energy dissipation in multiaxial fatigue tests of AISI 304L stainless steel bars, Procedia Structural Integrity 13 (2018) 1638-1643.

[19] P. Bayati, A. Jahadakbar, M. Barati, M. Nematollahi, L. Saint-Sulpice, M. Haghshenas, S.A. Chirani, M.J. Mahtabi, M. Elahinia, Toward low and high cycle fatigue behavior of SLM-fabricated NiTi:

considering the effect of build orientation and employing a self-heating approach, International Journal of Mechanical Sciences (2020) 105878.

[20] M. Naderi, M. Amiri, M. Khonsari, On the thermodynamic entropy of fatigue fracture, Proceedings of the Royal Society A: Mathematical, Physical and Engineering Sciences 466(2114) (2010) 423-438.

[21] C. Basaran, C.Y. Yan, A thermodynamic framework for damage mechanics of solder joints, Trans. of ASME-Journal of Electronic Packaging 120 (1998) 379-384.

[22] C. Basaran, S. Nie, An irreversible thermodynamics theory for damage mechanics of solids, International Journal of Damage Mechanics 13(3) (2004) 205-223.

[23] N. Bin Jamal M, A. Kumar, C. Lakshmana Rao, C. Basaran, Low Cycle Fatigue Life Prediction Using Unified Mechanics Theory in Ti-6Al-4V Alloys, Entropy 22(1) (2020) 24.

[24] X. Wang, H. Ran, C. Jiang, Q. Fang, An energy dissipation-based fatigue crack growth model, International Journal of Fatigue 114 (2018) 167-176.

[25] B. Hajshirmohammadi, M. Khonsari, On the entropy of fatigue crack propagation, International Journal of Fatigue 133 (2020) 105413.

[26] B. Hajshirmohammadi, M. Khonsari, Thermographic evaluation of metal crack propagation during cyclic loading, Theoretical and Applied Fracture Mechanics 105 (2020) 102385.

[27] M. Liakat, M. Naderi, M. Khonsari, O. Kabir, Nondestructive testing and prediction of remaining fatigue life of metals, Journal of Nondestructive Evaluation 33(3) (2014) 309-316.

[28] D. Rigon, G. Meneghetti, An engineering estimation of fatigue thresholds from a microstructural size and Vickers hardness: application to wrought and additively manufactured metals, International Journal of Fatigue 139 (2020) 105796.

[29] J. Lemaitre, J.-L. Chaboche, Mechanics of solid materials, Cambridge University Press 1994.

[30] M. Mehdizadeh, M. Khonsari, On the role of internal friction in low-and high-cycle fatigue, International Journal of Fatigue 114 (2018) 159-166.

[31] A.P. Jirandehi, M. Mehdizadeh, M. Khonsari, Temperature-induced buckling of ductile metals during cyclic loading and the subsequent early fracture, International Journal of Mechanical Sciences 176 (2020) 105525.

[32] V. Wan, M. Cuddihy, J. Jiang, D. MacLachlan, F. Dunne, An HR-EBSD and computational crystal plasticity investigation of microstructural stress distributions and fatigue hotspots in polycrystalline copper, Acta Materialia 115 (2016) 45-57.

[33] R.v. Mises, Mechanik der plastischen Formänderung von Kristallen, ZAMM-Journal of Applied Mathematics and Mechanics/Zeitschrift für Angewandte Mathematik und Mechanik 8(3) (1928) 161-185. 
[34] J. Bishop, R. Hill, CXXVIII. A theoretical derivation of the plastic properties of a polycrystalline face-centred metal, The London, Edinburgh, and Dublin Philosophical Magazine and Journal of Science 42(334) (1951) 1298-1307.

[35] A. Esin, W. Jones, A statistical approach to micro-plastic strain in metals, Journal of Strain Analysis 1(5) (1966) 415-421.

[36] W. mathematica, Mathematica User Documentation-NDSolve Options for Finite Elements, 2020.

[37] T. Letcher, M.H. SHEN, O. Scott-Emuakpor, T. George, C. Cross, An energy-based critical fatigue life prediction method for AL6061-T6, Fatigue \& Fracture of Engineering Materials \& Structures 35(9) (2012) 861-870.

[38] O. Scott-Emuakpor, T. George, C. Cross, M.-H. Shen, Analysis of strain energy behavior throughout a fatigue process, Experimental mechanics 51(8) (2011) 1317-1323.

[39] M. Liakat, M. Khonsari, On the anelasticity and fatigue fracture entropy in high-cycle metal fatigue, Materials \& design 82 (2015) 18-27.

[40] R. Munier, C. Doudard, S. Calloch, B. Weber, Determination of high cycle fatigue properties of a wide range of steel sheet grades from self-heating measurements, International Journal of Fatigue 63 (2014) 46-61.

[41] R. Munier, C. Doudard, S. Calloch, B. Weber, Identification of the micro-plasticity mechanisms at the origin of self-heating under cyclic loading with low stress amplitude, International Journal of Fatigue 103 (2017) 122-135. 